\title{
Effects of Phosphorus on tensile and stress rupture properties of GH4169 alloy
}

\author{
Cheng Tang, Jinhui Du*, Qun Deng, Zhongnan Bi, Minqing Wang \\ High Temperature Materials Research Institute, Central Iron and Steel Research Institute, Beijing, \\ China, 100081* Corresponding auther. Tel: +86 10 62184622; fax: +86 1062188576. \\ E-mail address: superalloy_1@163.com (J.H. Du).*superalloy_1@163.com
}

Key words: GH4169 alloys; Phosphorus; tensile; stress rupture; fractograph

\begin{abstract}
The influence of $\mathrm{P}$ on tensile properties at room temperature and $650^{\circ} \mathrm{C}$ as well as the effects of $\mathrm{P}$ on rupture properties at $650^{\circ} \mathrm{C} / 690 \mathrm{MPa}$ of $\mathrm{GH} 4169$ alloy with standard heat treatment (STD) and direct aging heat treatment (DA) were investigated in this paper. Mechanism of the influence of $\mathrm{P}$ was also undertaken with microstructure and fractograph analysis. The results show that $\mathrm{P}$ content has little effect on tensile properties of alloys. While the stress rupture life improves significantly with an increase of $\mathrm{P}$ content due to grain boundary segregation of $\mathrm{P}$ increasing grain boundary bonding force. And P has less influence on stress rupture life of GH4169 alloy as STD than that as DA, which may be relevant to the enrichment of $\mathrm{P}$ on $\delta$ phase interface. Increasing $\mathrm{P}$ content from $0.006 \%$ to $0.019 \%$, the stress rupture failure mode shows mainly transgranular fracture, decreased fraction of fine microvoids and deep dimple structure arises gradually.
\end{abstract}

\section{Introduction}

Alloy GH4169 consists mainly of a face centered cubic (fcc) matrix and three major intermetallic phases, namely the metastable $\gamma^{\prime \prime}\left(\mathrm{DO}_{22}\right.$ structure) phase and $\gamma^{\prime}\left(\mathrm{L}_{2}\right.$ structure) phase and the equilibrium $\delta\left(\mathrm{DO}_{\mathrm{a}}\right.$ structure) phase. It has high strength, high ductility, good antioxidation capability and excellent fabrication characteristics below $650^{\circ} \mathrm{C}$. Due to these attractive properties, it is the most successful and popular alloy in high-temperature field, widely used in aerospace, power generation and petrochemical industry and other key areas [1].

As domestic economy and national defense develop, there arises a new demand to advance the performance of aircraft engine, especially to improve its reliability and prolong its service life. GH4169 alloys have been extensively used as an important structural material in aero-engines such as disks, blades, and shafts, so it is of great importance to increase stress rupture life of this alloy [2].

Many researchers have indicated that increasing $\mathrm{P}$ content properly will improve mechanical properties of alloy GH4169 significantly, especially stress rupture life, contrary to a past view that regarded $\mathrm{P}$ as a detrimental element which caused grain boundary embrittlement. But investigators usually focus on GH4169 alloy as STD when they study the effect of P, and little attention has been paid to DA GH4169 alloy. There is still some controversy to the mechanism of P [3-7]. This paper studies the rule of P on tensile and stress rupture properties of GH4169 alloy with different heat treatment. It also discusses the effect mechanism of $\mathrm{P}$, and provides reference to improve the performance of GH4169 alloy.

\section{Experimental procedure}

The ingots were vacuum induction melted (VIM) with each weight of $50 \mathrm{Kg}$. The chemistry of these blanks is listed in Table 1 . P level covers a range of $0.006 \%$ to $0.019 \%$ in weight percent and is the only apparent variable among compositions.

All test alloys were homogenized for $24 \mathrm{hrs}$ at $1160^{\circ} \mathrm{C}$ and for $72 \mathrm{hrs}$ at $1190^{\circ} \mathrm{C}$ and rolled to $18 \mathrm{~mm}$ diameter bars. Specimen blanks for tensile and stress rupture tests were cut from the bars and then given the following different heat treatment. One kind is standard heat treatment: solutionized 
at $960^{\circ} \mathrm{C}$ for $1 \mathrm{hr}$, air cooled and then aged for $8 \mathrm{hrs}$ at $720^{\circ} \mathrm{C}$, furnace cooled to $620^{\circ} \mathrm{C}$, held at $620^{\circ} \mathrm{C}$ for $8 \mathrm{hrs}$, air cooled. The other kind is direct aging heat treatment: aged for $8 \mathrm{hrs}$ at $720^{\circ} \mathrm{C}$, furnace cooled to $620^{\circ} \mathrm{C}$, held at $620^{\circ} \mathrm{C}$ for $8 \mathrm{hrs}$, air cooled.

These test samples with different heat treatment were then electrolytically etched in $80 \mathrm{ml}$ $\mathrm{HCl}+13 \mathrm{ml} \mathrm{HF}+7 \mathrm{ml} \mathrm{HNO}_{3}$ solution at a voltage of $1.6 \mathrm{~V}$ for about five seconds. Their microstructure was examined with optical microscopy (OM) and scanning electron microscopy (SEM). Tensile tests were performed at room temperature and $650^{\circ} \mathrm{C}$, and stress rupture tests were conducted in air at $650^{\circ} \mathrm{C}$ and at constant initial applied stress level of $690 \mathrm{MPa}$. The fracture surface of stress rupture test specimens was also observed by SEM.

Table 1. Chemical composition of the investigated GH4169 alloys (wt. \%)

\begin{tabular}{ccccccccccc}
\hline $\begin{array}{c}\text { Alloy } \\
\text { No. }\end{array}$ & $\mathbf{P}$ & $\mathbf{C}$ & $\mathbf{C r}$ & $\mathbf{N i}$ & $\mathbf{M o}$ & $\mathbf{N b}$ & $\mathbf{T i}$ & $\mathbf{A l}$ & $\mathbf{B}$ & $\mathbf{F e}$ \\
\hline $\mathbf{1}$ & 0.006 & 0.028 & 19.03 & 52.57 & 3.06 & 5.39 & 0.99 & 0.54 & 0.0035 & Bal. \\
$\mathbf{2}$ & 0.0092 & 0.029 & 18.94 & 52.40 & 3.03 & 5.39 & 0.98 & 0.54 & 0.0032 & Bal. \\
$\mathbf{3}$ & 0.0110 & 0.027 & 18.95 & 52.48 & 3.07 & 5.41 & 0.99 & 0.55 & 0.0035 & Bal. \\
$\mathbf{4}$ & 0.0190 & 0.027 & 19.01 & 52.42 & 3.07 & 5.39 & 0.98 & 0.52 & 0.0036 & Bal.
\end{tabular}

\section{Results}

The typical optical microstructure of samples before heat treatment is shown in Fig. 1. The alloys contain uniform equiaxed grains about ASTM10 level, and visually no difference exists, precluding possible interference caused by original grain difference.
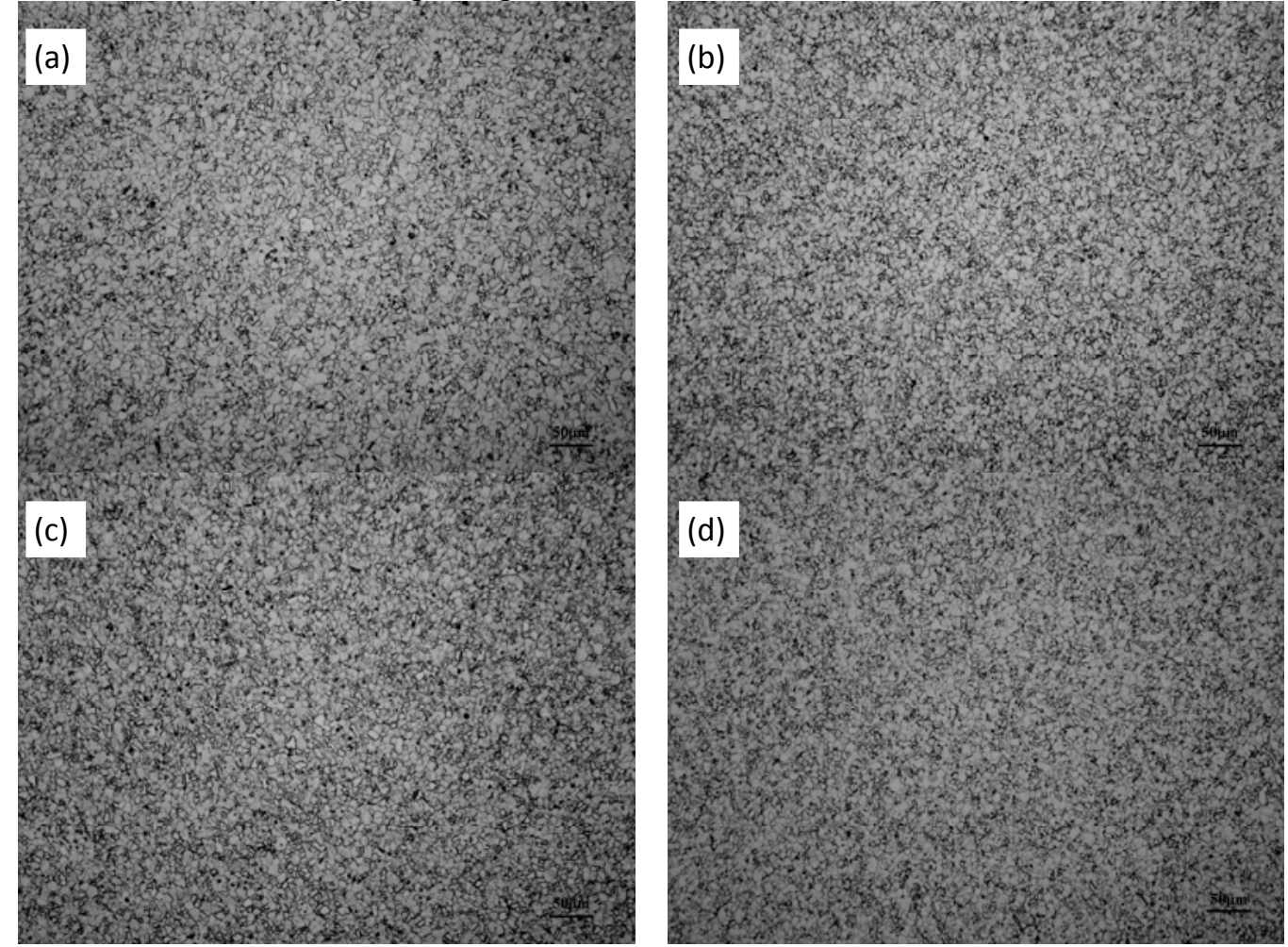

Fig.1 OM micrographs of the as-rolled GH4169 alloys

\section{Microstructure}
(a) alloy No. 1
(b) alloy No.2
(c) alloy No.3
(d) alloy No.4

The microstructure of test alloys with different heat treatment was shown in Figures 2 and 3, representing DA and STD respectively. Owing to merely direct aging between $620^{\circ} \mathrm{C}$ and $720^{\circ} \mathrm{C}$, there is almost no $\delta$ phase in grains or at boundaries and the microstructure was basically the same as the rolled (Fig. 2a-d). However, when solutionized at $960^{\circ} \mathrm{C}$, a lot of short rod-like $\delta$ phases precipitated at grain boundaries, whose quantity and morphology present no apparent relationship with P content (Fig. 3a-d). 

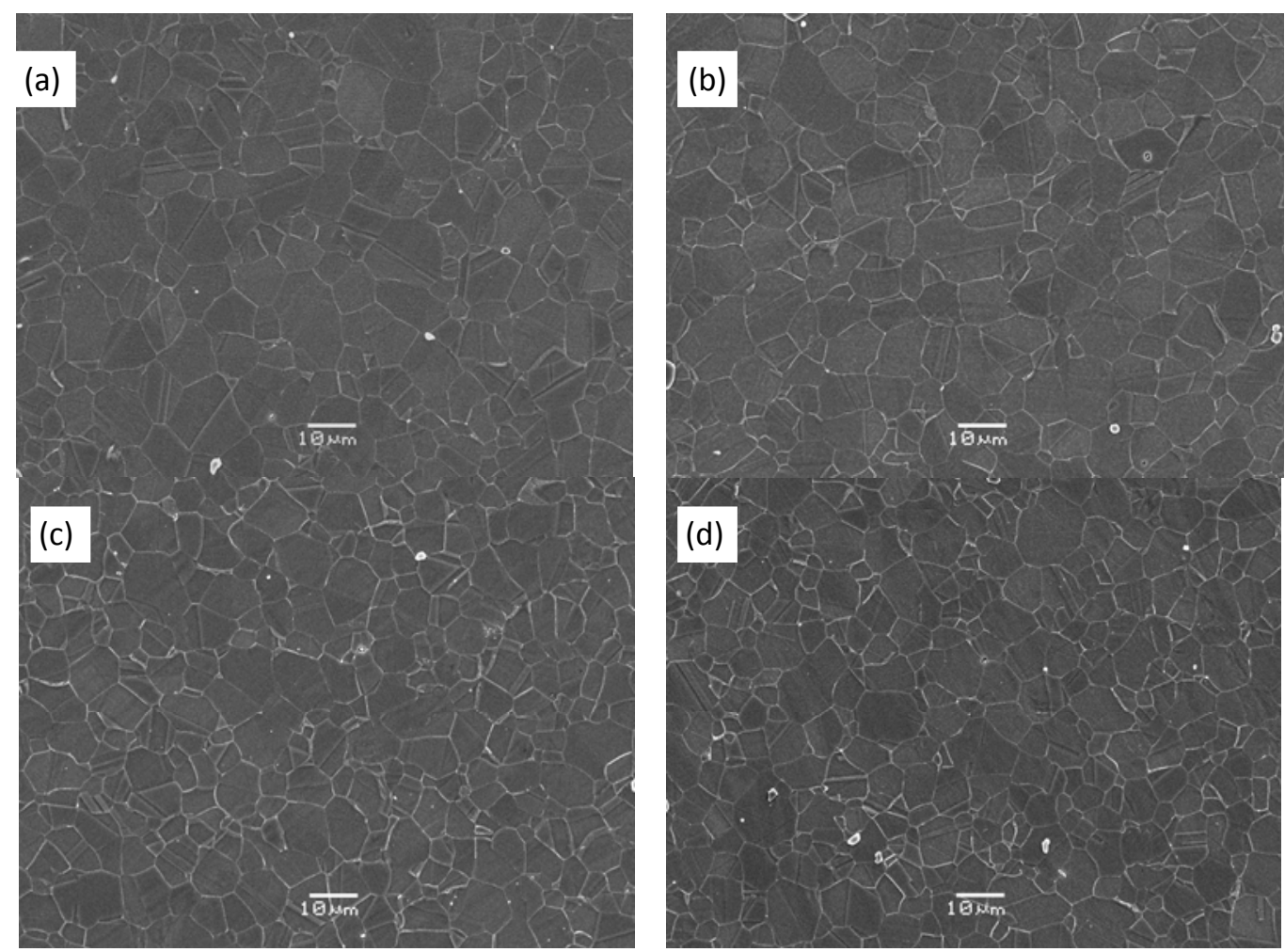

Fig.2 SEM micrographs of test alloys as direct aging treatment $\begin{array}{llll}\text { (a) alloy No. } 1 & \text { (b) alloy No.2 } & \text { (c) alloy No.3 } & \text { (d) alloy No.4 }\end{array}$
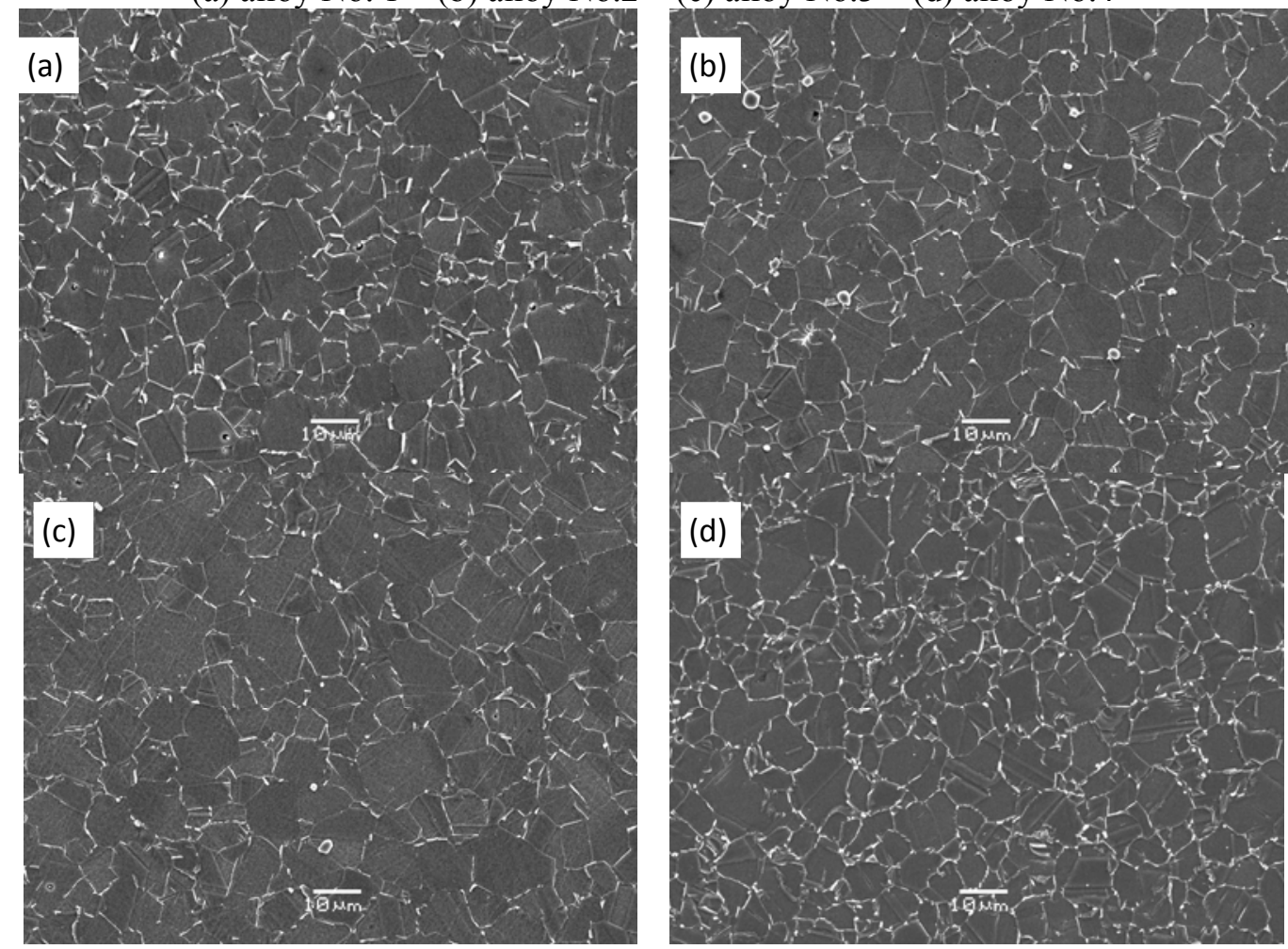

Fig.3 SEM micrographs of test alloys as standard heat treatment

\section{Tensile Properties}
(a) alloy No. 1
(b) alloy No.2
(c) alloy No.3
(d) alloy No.4

The tensile test results are shown in Fig. 4 and 5. Strength and ductility of GH4169 alloys as DA and STD at room temperature stay nearly at the same level, seemingly immune to the change of $\mathrm{P}$ content (Fig. 4). Room temperature tensile strength and elongation of samples as DA are slightly higher than those as STD, when compared with the same $\mathrm{P}$ content. Tensile properties at $650^{\circ} \mathrm{C}$ also remain relatively unaffected by $\mathrm{P}$ level. As shown in Fig. 5, tensile ductility at $650^{\circ} \mathrm{C}$ varies a little larger than room temperature. The difference of elongation between the maximum and minimum 
value is about $4 \%$, which should be attributed to experimental error, since no obvious regularity occurs. Within the test range, (P: 60-190 ppm), no trend is observed that tensile ductility would decrease with an increase of $\mathrm{P}$ level.
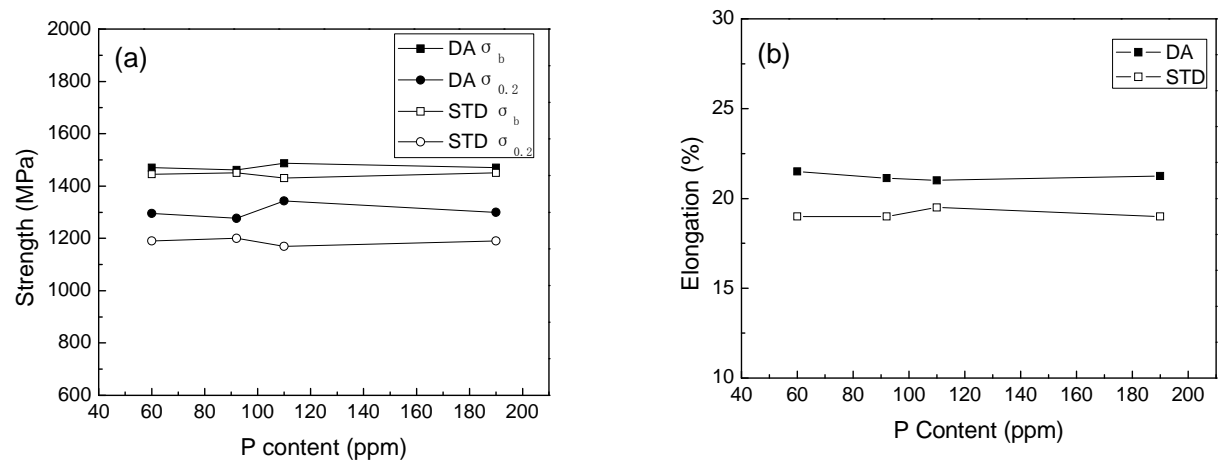

Fig.4 Relationship of room temperature tensile properties of GH4169 with P content

(a) strength (b)elongation
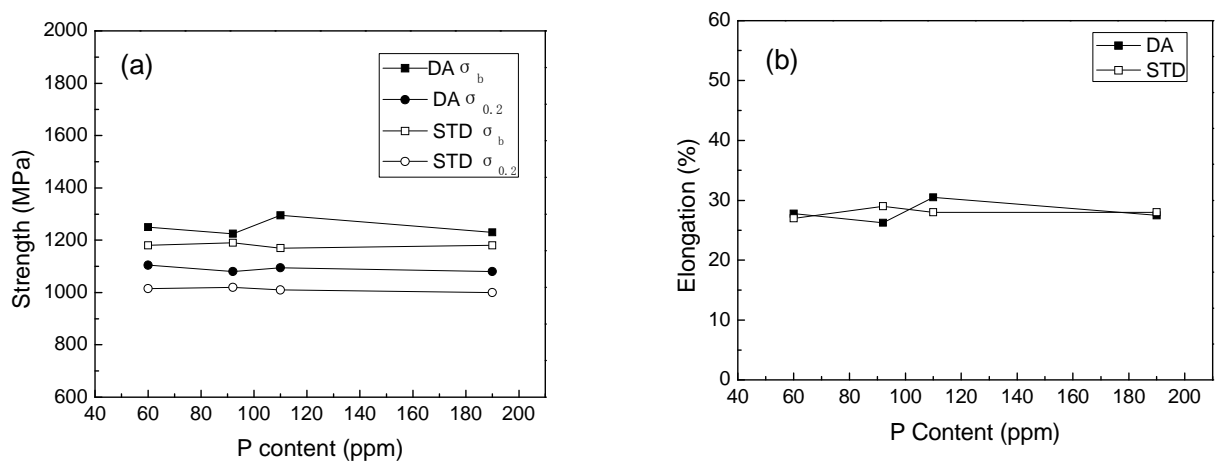

Fig. 5 Relationship of $650^{\circ} \mathrm{C}$ tensile properties of GH4169 with P content

\section{Stress rupture properties}

(a) strength (b) elongation

The most significant effect of P in GH4169 alloys exists in stress rupture properties, as shown in Fig. 6. As a whole, alloys as DA have a higher stress rupture life than those as STD, while lower in rupture ductility. The stress rupture life of two heat-treated state GH4169 alloys presents a certain extent of growth with an increased $\mathrm{P}$ level. And an inflection point arises at about $100 \mathrm{ppm} \mathrm{P}$, where growth rate of stress rupture life begins to decrease. By contrast, stress rupture life of DA samples is far more susceptible to P level than STD alloys. In other words, under the same conditions, DA samples grow more steeply and faster. As for DA alloys, the stress rupture life reaches a maximum of 1658 hours at $190 \mathrm{ppm}$ P, which is over three times more than the minimum of 516 hours at 60 ppm P. Though the growth trend of STD alloys is slower than DA alloys, it also increases from 164 hours at $60 \mathrm{ppm} P$ to 484 hours at $190 \mathrm{ppm}$ P. The rupture ductility also slightly improves as $\mathrm{P}$ content goes up, and remains basically unchanged after the turning point at about $100 \mathrm{ppm} \mathrm{P}$, as shown in Fig. 7. No decrease of rupture reduction in area is observed, when P level changes from 60 to $190 \mathrm{ppm}$. 


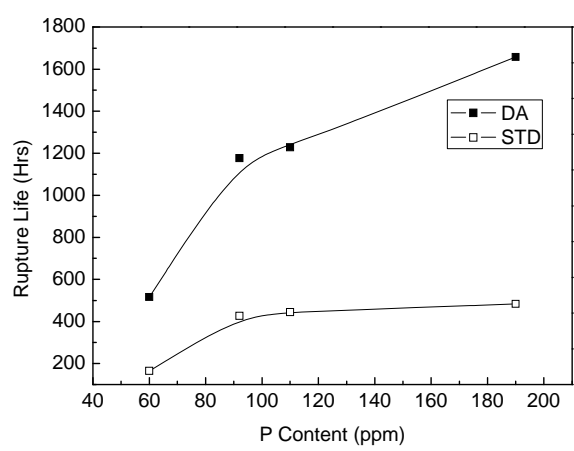

Fig.6 Relationship of stress rupture life for GH4169 with $\mathrm{P}$ content under $650^{\circ} \mathrm{C}, 690 \mathrm{MPa}$ test condition

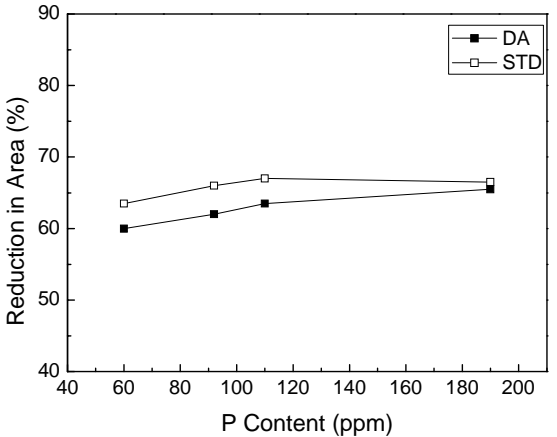

Fig.7 Relationship of stress rupture reduction in area for $\mathrm{GH} 4169$ with $\mathrm{P}$ content under $650^{\circ} \mathrm{C}$, $690 \mathrm{MPa}$ test condition

Early work by Cao [3] reported that intergranular cracking existed at the surface of the test samples within $0.003 \% \mathrm{P}$, and then diminished gradually as the $\mathrm{P}$ level increased further. Figure 8 illustrates that rupture fractures at $650^{\circ} \mathrm{C} / 690 \mathrm{MPa}$ occur mainly by transgranular dimple fracture, but the morphology of the dimple differs greatly in high and low $\mathrm{P}$ alloys. In low $\mathrm{P}$ alloys, the fracture surface is consisted of mainly fine microvoids (Fig. 8a). With an increase of $P$ content, fine microvoids are replaced by large ones gradually, and deep dimple structure arises more frequently (Fig. 8d). The increased quantity of deep dimple fracture will result in the improvement of rupture ductility of the alloys, corresponding to the rule shown in Fig. 7.
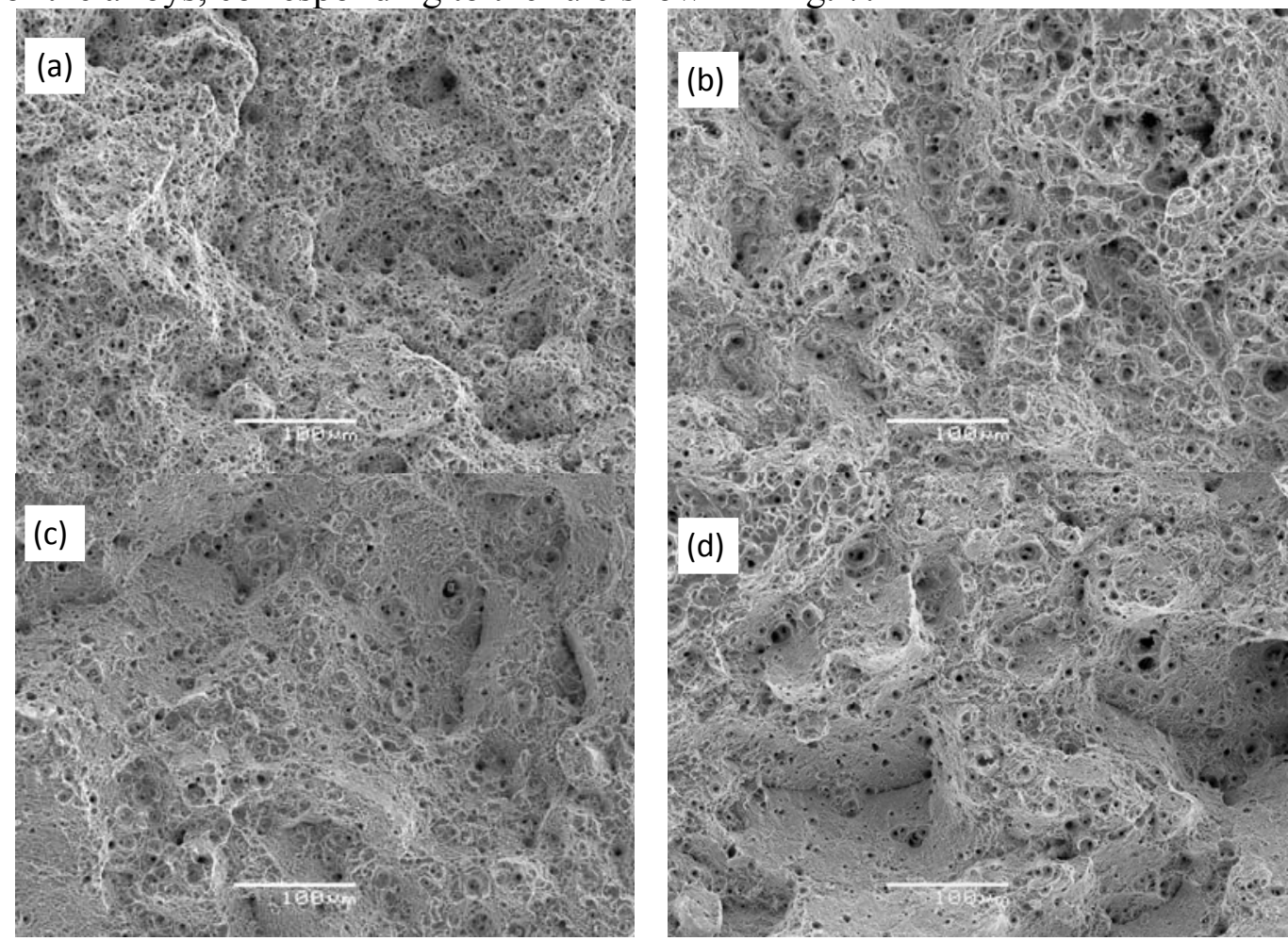

Fig. 8 SEM fractographs of DA GH4169 alloy at $650^{\circ} \mathrm{C} / 690 \mathrm{MPa}$
(a) alloy No. 1
(b) alloy No.2
(c) alloy No.3
(d) alloy No.4

\section{Discussions}

\section{Effect of $P$ on the tensile properties}

GH4169 alloy, a precipitation-strengthened nickel-based superalloy, is primarily strengthened by $\gamma^{\prime \prime}$ phase, and assisted $\gamma^{\prime}$ phase. Strength of the alloy is closely related to the amount, distribution, and morphology of the strengthening phase. L.Viskari [8] indicated that there was no clear enrichment of P at the $\gamma / \gamma^{\prime}$ and $\gamma / \gamma^{\prime \prime}$ interfaces, and no obvious effect on grain size, so P had little impact on the strength of GH4169 alloy, as shown in Fig. 4 and 5. 
Within the test range, P also does not affect the elongation of alloy GH4169 markedly, which is in agreement with the results of $\mathrm{Cao}$ and Xie. But $\mathrm{Cao}$ indicated further that when $\mathrm{P}$ reached 200-300 ppm, $650^{\circ} \mathrm{C}$ tensile ductility began to decline. And it might be in connection with that $\mathrm{P}$ improved the degree of microsegregation, promoting Laves phase formation $[3,6]$.

\section{Effect of $P$ on the stress rupture properties}

$P$ used to be treated as a detrimental element in superalloys, which might cause grain boundary embrittlement, and weaken hot working performance. However, some recent studies reported that adding $\mathrm{P}$ could improve the intergranular cracking resistance and creep resistance [6-8]. But the mechanism of $P$ is still unclear.

Auger analysis indicated $\mathrm{P}$ concentrated mainly at grain boundaries and no other significant element segregation was observed [9]. The phenomenon that $\mathrm{P}$ segregation to grain boundaries promotes the stress rupture properties of alloy demonstrates the influence of $\mathrm{P}$ is achieved through grain boundary. Some investigators reported that the beneficial effects of $\mathrm{P}$ have relations with the morphology of $\delta$ phase [10-12]. It was revealed that increasing P content makes $\delta$ phase smaller, more uniform, and change from the film-like to the lath-like. But in this paper, there seems no distinct correlation between morphology of $\delta$ phase and P content in STD samples (Fig.3). Furthermore, an addition of $\mathrm{P}$ still improves the stress rupture life in DA samples, though there is almost no $\delta$ phase precipitated at grain boundary (Fig. 2), and the extent varies even more greatly than STD alloys, as shown in Figure 6. Therefore, it can be inferred that the impact of $\mathrm{P}$ on $\delta$ phase morphology is not a major factor in prolonging stress rupture life.

Other researchers consider the effect of $\mathrm{P}$ may come from its direct action to grain boundary [3, 13]. The segregation of $P$ to grain boundary increases the grain boundary cohesion by impeding dislocation motion, resulting in the improvement of stress rupture life. As P-dislocation interaction increases, stress rupture life rises as well. Considering the similar size of original grains (Fig. 1), the microvoid may be formed by creep at grain boundaries during stress rupture test. Hence, as $\mathrm{P}$ content increases, the decreased fraction of fine microvoids could signify higher grain boundary cohesion and longer stress rupture life (Fig. 8).

As this study demonstrates, there is a large difference in the sensitivity of P between DA and STD samples. Under the same test conditions, stress rupture life of DA samples, as a whole, has a higher value than STD samples. This is mainly determined by the differences of strength and morphology. Moreover, the stress rupture life of DA alloys without $\delta$ phase grows more steeply and faster than STD alloys with $\delta$ phase. It means that $\delta$ phase may affect the mechanism of P to stress rupture properties. L. Viskari [8] observed alloy 718 (i.e. GH4169) and Allvac 718Plus in atomic scale with atom probe tomography (APT), and revealed that $\mathrm{P}$ segregated at $\gamma / \gamma$ grain boundaries of the DA samples and $\gamma / \delta$ phase boundaries of the STD samples. In fact, the view that adding P will change the morphology of $\delta$ phase also proves the enrichment of $\mathrm{P}$ at $\gamma / \delta$ phase boundaries $[9,10]$.

Thus, it can be considered that as P to some extent enriches on $\delta$ phase interface in STD alloys, the quantity of $\mathrm{P}$ segregating at grain boundaries will decrease accordingly. However $\mathrm{P}$ gathers primarily at grain boundaries in DA alloys. In other words, when compared in the same P content, DA alloys have more effective P than STD alloys, resulting in a more obvious increase of stress rupture life. This opinion agrees well with that adding proper $\mathrm{P}$ will enhance grain boundary cohesion.

Therefore the increase of P content promotes the stress rupture life of GH4169 alloy, the main reason is segregation of $\mathrm{P}$ in the grain boundary, rather than of $\mathrm{P}$ in $\delta$ phase. In contrast, $\delta$ phase existing at grain boundary will weaken the effect of $\mathrm{P}$ to improve stress rupture properties.

\section{Conclusions}

1) P level (60-190 ppm) has little effect on room temperature and $650^{\circ} \mathrm{C}$ tensile properties of both DA and STD GH4169 alloys.

2) Adding $\mathrm{P}$ improves stress rupture life of GH4169 alloys with different heat treatment at $650^{\circ} \mathrm{C} / 690 \mathrm{MPa}$ significantly. 
3) As P content increases, growth rate of stress rupture life for DA samples is higher than STD samples. This may be related to the enrichment of $\mathrm{P}$ at $\gamma / \delta$ phase boundaries.

\section{Acknowledgments}

The authors would like to acknowledge the financial support of the National Important Base Research and Development Program of China under Contract Number 2010CB631203 and Beijing Key Laboratory of Advanced High Temperature Materials.

\section{Reference}

[1] M. Sundararaman, P. Mukhopadhyay and S. Banerjee. Precipitation and room temperature deformation behavior of Inconel 718[A]. Superalloys 718, 625, 706 and Various Derivatives [C]. Edited by E.A. Loria, TMS, 1994: 419-440.

[2] S. Kalluri, K.B.S. Rao, G.R. Halford, et al. Deformation and damage mechanisms in Inconel 718 superalloy[A]. Superalloys 718, 625, 706 and Various Derivatives [C]. Edited by E.A. Loria, TMS, 1994: 593-606.

[3] W.D. Cao, R.L. Kennedy. The effect of phosphorous on mechanical properties of alloy 718[A]. Superalloys 718, 625, 706 and Various Derivatives [C]. Edited by E.A. Loria, TMS, 1994: 463-477.

[4] C.G. Mckamey, C.A. Carmichael, W.D. Cao, et al. Creep properties of phosphorus + boronmodified alloy 718[J]. Scripta Materialia, 1998, 38: 485-491.

[5] X.S. Xie, X.B. Liu, Y.H. Hu, et al. The role of phosphorus and sulfur in inconel 718[A]. Superalloys 1996 [C]. Edited by R.D. Kissinger, TMS, 1996: 599-606.

[6] X.S. Xie, X.B. Liu, J.X. Dong, et al. Segregation behavior of phosphorus and its effect on microstructure and mechanical properties in alloy system Ni-Cr-Fe-Mo-Nb-Ti-Al[A]. Superalloys 718, 625, 706 and Various Derivatives [C]. Edited by E.A. Loria, TMS, 1997: 531-542.

[7] Z.Q. Hu, H.W. Song, S.R. Guo, et al. Role of P, S and B on creep behavior of alloy 718 [J]. Journal of Materials Science \& Technology, 2001, 17(4): 399-402.

[8] L. Viskari, K. Stiller. Atom probe tomography of Ni-base superalloys Allvac 718Plus and alloy 718 [J]. Ultramicroscopy, 2011, 111(6): 652-658.

[9] B. Tang, J.X. Dong, Y.H. Hu, et al. Mechanical properties of low phosphorous and conventional Inconel 718 deformation alloys [J]. The Chinese Journal of Nonferrous Metals. 1998, 8(3): 385-389.

[10] H.W. Song, S.R. Guo, D.Z. Lu, et al. Effects of phosphorus content on stress rupture and creep properties of In718 [J]. The Chinese Journal of Nonferrous Metals. 2000, 10(3): 301-305.

[11] B. Tang, X.B. Liu, J.X. Dong, et al. Effect of phosphorous on mechanical behavior of superalloy GH169 (Inconel 718) [J]. Ordnance Material Science and Engineering. 1997, 20(2): 8-12.

[12] W.R. Sun, S.R. Guo, J.H. Lee, et al. Effects of phosphorus on the $\delta-\mathrm{Ni}_{3} \mathrm{Nb}$ phase precipitation and the stress rupture properties in Alloy 718 [J]. Materials Science and Engineering. 1998, A247: 173-179.

[13] J. Heaney, W. Buttrill, J. Russell, et al. Influence of phosphorus on creep performance of DA alloy 718 [A]. Superalloys 718, 625, 706 and Various Derivatives [C]. Edited by E.A. Loria, TMS, 1994: 687-698. 